\title{
REVIEW
}

\section{Testicular biopsy: clinical practice and interpretation}

\author{
Gert R Dohle $^{1}$, Saad Elzanaty ${ }^{2}$ and Niels J van Casteren ${ }^{1}$
}

Testicular biopsy was considered the cornerstone of male infertility diagnosis for many years in men with unexplained infertility and azoospermia. Recent guidelines for male infertility have limited the indications for a diagnostic testicular biopsy to the confirmation of obstructive azoospermia in men with normal size testes and normal reproductive hormones. Nowadays, testicular biopsies are mainly performed for sperm harvesting in men with non-obstructive azoospermia, to be used for intracytoplasmic sperm injection. Testicular biopsy is also performed in men with risk factors for testicular malignancy. In a subgroup of infertile men, there is an increased risk for carcinoma in situ of the testis, especially in men with a history of cryptorchidism and testicular malignancy and in men with testicular atrophy. Ultrasonographic abnormalities, such as testicular microlithiasis, inhomogeneous parenchyma and lesions of the testes, further increase the risk of carcinoma in situ (CIS) in these men. For an accurate histological classification, proper tissue handling, fixation, preparation of the specimen and evaluation are needed. A standardized approach to testicular biopsy is recommended. In addition, approaches to the detection of CIS of the testis testicular immunohistochemistry are mandatory. In this mini-review, we describe the current indications for testicular biopsies in the diagnosis and management of male infertility.

Asian Journal of Andrology (2012) 14, 88-93; doi:10.1038/aja.2011.57; published online 12 December 2011

Keywords: carcinoma in situ of the testis; diagnosis; male infertility; testicular sperm extraction; testicular biopsy; testicular germ cell malignancies

\section{INTRODUCTION}

Unexplained male infertility is present in $30 \%-40 \%$ of men with abnormal semen parameters. ${ }^{1}$ Potential explanations for unexplained male infertility are endocrine disruption of gonadal development during early pregnancy, due to environmental pollution and genetic factors. Both genetic and environmental causes of infertility can result in testicular dysgenesis, and consequently in infertility, hypogonadism and an increased risk of testicular malignancy. ${ }^{2}$

Testicular biopsy may be part of the diagnostic process of infertile men, but usually testicular histology does not explain the real cause of infertility. It merely confirms a disturbance of spermatogenesis in men with low sperm concentrations and elevated follicle-stimulating hormone. Testicular biopsy plays a distinctive role in the diagnosis of obstructive azoospermia: in these men, surgical repair of the genital tract may be feasible and result in the presence of spermatozoa in the semen and spontaneous pregnancies. ${ }^{3}$ In most cases, however, a routine diagnostic testicular biopsy will not alter therapeutic options.

For men with non-obstructive forms of severe oligozoospermia and azoospermia, intracytoplasmic sperm injection (ICSI) is the only alternative if viable spermatozoa are present. ${ }^{4}$ In the era of ICSI, testicular biopsy is usually performed in men with non-obstructive azoospermia (NOA) for spermatozoa extraction, the testicular sperm extraction (TESE) procedure. In about $50 \%-60 \%$ of men with NOA and in $100 \%$ of men with OA, spermatozoa can be retrieved from the testes and used for ICSI. In this review, we will discuss current indications for testicular biopsy, the interpretation of testicular histology for infertility diagnosis, the clinical (prognostic) value of the results of testicular biopsy and the detection of carcinoma in situ (CIS) of the testis.

\section{TECHNIQUE}

Testicular biopsy can be performed under local and general anaesthesia. Usually, the procedure is performed as day-care surgery in an outpatient clinic setting. For a diagnostic testicular biopsy, a scrotal incision of $2-3 \mathrm{~cm}$ could allow enough exposure of the tunica albuginea of the testis. A small incision in the capsule of the testicular of about $0.5 \mathrm{~cm}$ is made for obtaining a biopsy of about $3 \times 3 \times 3 \mathrm{~mm}$. For adequate classification of spermatogenesis, the removed tissue should contain at least 100 seminiferous tubules. ${ }^{5}$ The tissue should not be squeezed with a forceps since this may disrupt testicular tissue architecture and hamper proper evaluation of the seminiferous tubules. The wound is closed with absorbable sutures.

An alternative to an open diagnostic testicular biopsy could be a transcutaneous puncture of the testis with either a true-cut needle or a fine needle aspiration (FNA). ${ }^{6}$ The advantage of FNA of the testis is that is does not require surgical equipment and experience, and can be performed in an outpatient setting under local anaesthesia. ${ }^{7}$ Rammouu-Kinia et al. ${ }^{8}$ demonstrated a correlation of $88.5 \%$ between fine needle biopsies and normal histology in different patient groups. FNA may also be helpful in the diagnosis of small testicular lesions. It is, however, unclear if FNA can also accurately detect CIS of the testis.

FNA of the testis, using a small butterfly needle attached to a syringe, may also be used to harvest spermatozoa for ICSI, especially in men with OA. ${ }^{6,9}$ The technique is, however, associated with a lower sperm retrieval rate in men with NOA compared to open biopsy techniques.

For TESE procedures, different techniques have been developed and compared. The microsurgical TESE seems to have the highest sperm retrieval rate and may limit damage to the testicular tissue.

${ }^{1}$ Department of Urology, Erasmus MC, 3000 CA Rotterdam, The Netherlands and ${ }^{2}$ Department of General Surgery, Urology Section, Kristianstad Central Hospital, Kristianstad SE 29185 , Sweden 
Table 1 Studies comparing conventional testicular sperm extraction (cTESE) to microsurgical testicular sperm extraction (mTESE) in regard to sperm retrieval rate (SRR)

\begin{tabular}{lcccccc}
\hline Study & \multicolumn{2}{c}{ cTESE } & & \multicolumn{2}{c}{ mTESE } \\
\cline { 2 - 3 } \cline { 5 - 6 } & $\mathrm{n}$ & SRR (\%) & & $\mathrm{n}$ & SRR (\%) \\
\hline Okada et al. $^{33}$ & 24 & 17 & & 74 & 45 \\
Ramasamy et al. $^{40}$ & 83 & 32 & & 460 & 58 \\
Tsujimura et al. & 37 & 35 & & 56 & 43 \\
Average SRR (\%) & \multicolumn{2}{c}{$40(16-63)$} & & & $48(42-58)$ \\
\hline
\end{tabular}

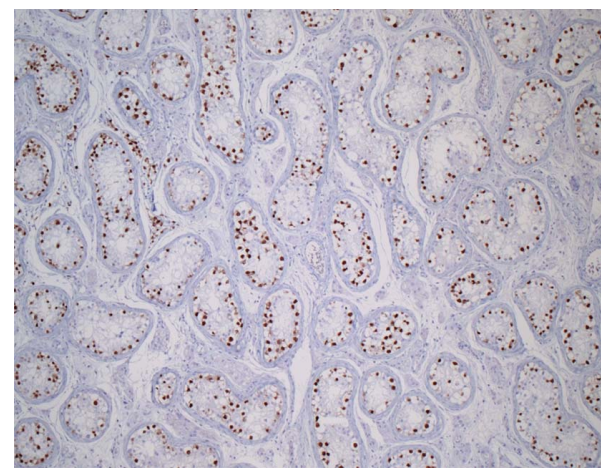

Figure 1 OCT 3/4 staining of carcinoma in situ cells in seminiferous tubules of the testis.

Spermatozoa can be retrieved from tubules that are dilated and this can be visualized with an operating microscope. This technique needs microsurgical skills and general anaesthesia is usually required. Table 1 summarizes the different sperm retrieval rates obtained by conventional TESE procedures and by microsurgical TESE. Especially small-size testes may benefit from microsurgical TESE procedures.

Performing a testicular biopsy does not have a high complication rate: sometimes bleeding and infection occur. Biopsies taken in small atrophic testicles might increase the risk of hypogonadism, which then results in life-long testosterone substitution. ${ }^{10}$ This concern should be considered in advance and discussed with the patient. The risk for hypogonadism after testicular biopsy specifically applies to TESE procedures performed in small-size testis. Ishikawa et al. ${ }^{11}$ demonstrated that the risk of hypogonadism is increased in patients with Sertoli cell-only syndrome and in
Klinefelter patients. In most patients, testosterone levels recover to prebiopsy levels within 1 year due to an elevation of luteinizing hormone LH. With age, these men may be at risk for late-onset hypogonadism. ${ }^{12}$ In patients with NOA, an assessment should be made between the risk of injury due to multiple-sited biopsies and the diagnostic and therapeutic benefits for the patient.

\section{TISSUE HANDLING}

All too frequently in clinical practice, the value of testicular biopsy is diminished as a result of poor biopsy specimen handling and incorrect interpretation of samples by pathologists, not thoroughly familiar with the reproductive tract histology. ${ }^{13}$ A standardized approach of the fixation and staining procedure of the biopsy and the classification of the specimen are needed. ${ }^{13,14}$

For a reliable evaluation, the biopsies taken should be uniformly provided to the pathologist. The specimen fixation is important as it can influence staining patterns. A standardized approach for fixation and staining of the specimen is desirable. ${ }^{15-17}$ The European Germ Cell Cancer Consensus Group advocates the use of Stieve's or Bouin's solution for fixation. ${ }^{18}$ The use of Stieve's solution might aid in preserving morphology, but hampers intranuclear staining methods if the fixation process is prolonged. Bouin's solution allows good fixation of the tissue for histological evaluation of spermatogenesis, but is infrequently used because of its reduced shelf-life and toxicity. ${ }^{19}$ Formalin is commonly used for fixation, but may cause shrinkage artefacts. This can be reduced by using neutral buffered formaldehyde. ${ }^{20}$ Also, immunohistochemistry with OCT $3 / 4$ for the detection of CIS could be false-negative if Stieve's or Bouin's solution is used. ${ }^{15}$

For the diagnosis of CIS, Dieckmann et al. ${ }^{21}$ proposed to take two biopsies in each testis to increases the chance of detecting CIS by $18 \%$. This, however, applies to normal-size testis and not to atrophic testis. Performing a two-sided biopsy in an atrophic testis might lead to testicular dysfunction and a single biopsy is recommended for routine diagnostic purposes. Routinely, haematoxylin-eosin staining is usually applied for evaluation of spermatogenesis. For the detection of CIS of the testis, additional staining procedures are recommended. ${ }^{22}$ CIS is difficult to identify in testicular biopsies. Several markers for CIS of the testis have been developed, including placental alkaline phosphatase, AP2-gamma and stem cell factor receptor c-KIT. ${ }^{23}$ In a recent study performed by our department, we found an extra diagnostic yield of $20 \%$ in identifying CIS in biopsies from infertile men using the OCT $3 /$ 4 marker. OCT $3 / 4$ is highly specific for CIS and currently, the best marker for CIS, seminomas and embryonal carcinomas (Figure 1). ${ }^{24}$
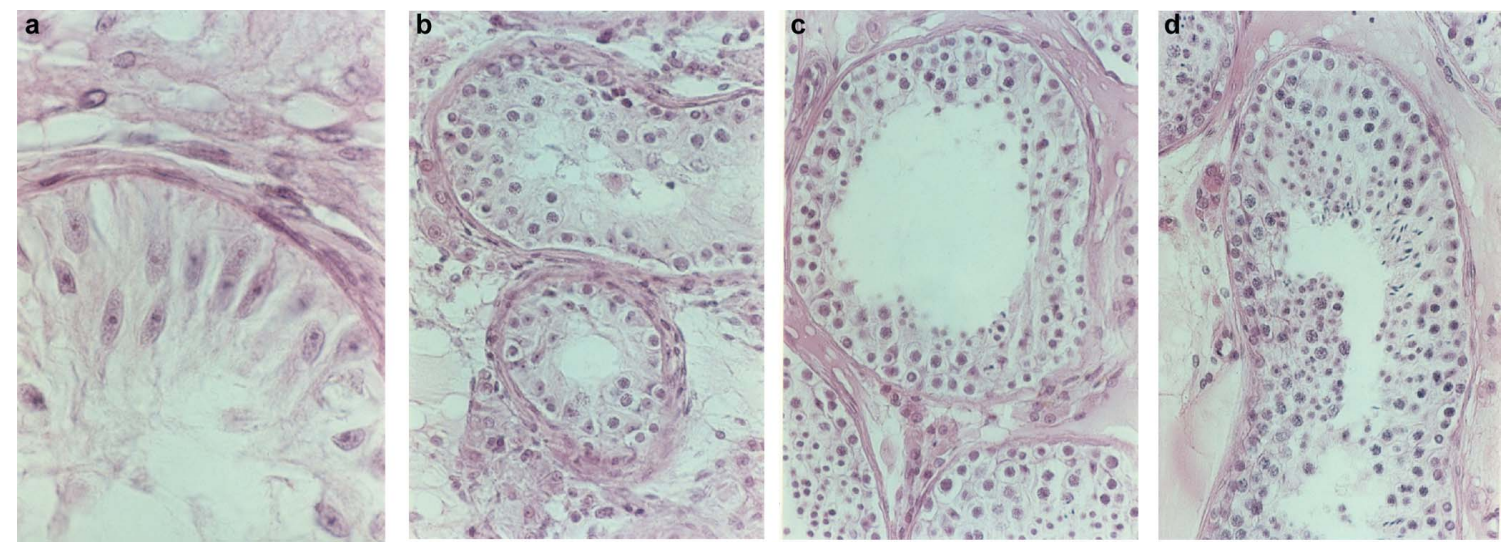

Figure 2 Several classification systems for scoring of spermatogenesis based on five main histological patterns of spermatogenesis. (a), Sertoli cell-only syndrome. (b), Maturation arrest. (c), Hypospermatogenesis. (d), Normal spermatogenesis. 
These markers are not $100 \%$ accurate in biopsies performed in newborn, as a neonatal germ with delayed development may resemble a CIS cell and display prolonged expression of immunohistochemical markers used for the diagnosis of CIS. Using the presence of stem cell factor, also known as KITLG, we recently have been able to differentiate between delayed matured germ cells and the earliest stages of malignant transformation. ${ }^{24}$

\section{SCORING OF SPERMATOGENESIS}

Several classification systems are described, ${ }^{25-29}$ all based on five main histological patterns of spermatogenesis: (i) absence of seminiferous tubules (tubular sclerosis); (ii) no germ cells within the seminiferous tubules (Sertoli cell-only syndrome) (Figure 2a); (iii) incomplete spermatogenesis, not beyond the spermatocyte stage (spermatogenic arrest) (Figure 2b); (iv) all germ cell stages present including spermatozoa, but there is a distinct decline in the number of germ cells (hypospermatogenesis) (Figure 2c); and (v) normal spermatogenesis (Figure 2d). In practice, these different stages of spermatogenesis often exist next to each other in a single biopsy (mixed pattern). This has resulted in a wide variation of classification of spermatogenesis by different pathologists and limits the diagnostic and prognostic value of the testicular biopsy.

A widely quoted and quantitative histological grading system is the Johnsen score; in at least 100 seminiferous tubules, the level of sperm maturation is graded between 1 and 10, according to the most advanced germ cell in the tubule. ${ }^{25}$ The total Johnsen score is then determined by dividing the total score by the number of evaluated tubules. An enormous drawback of the Johnsen scoring system, is that the mean tubule score may not reflect the true status of spermatogenesis: e.g., normal spermatogenesis can be found in a biopsy next to tubules with a Sertoli cell-only pattern. This results in a mean score indicating a severe disturbance of spermatogenesis. However, in the case of TESE sperm, harvesting is likely to occur in these men and the Johnsen score may not have a reliable predictive value for sperm recovery. ${ }^{30}$ Also the Johnsen score is quite labourintensive. Taking all these points into consideration, it has little clinical utility in the current fertility practice. The scoring system was modified by de Kretser and Holstein. ${ }^{26,27}$ Others have emphasized the importance of the main histological classification of the tubules with a focus on the predictive value of the biopsy for successful sperm harvesting. ${ }^{28-31}$

\section{INDICATIONS FOR TESTICULAR BIOPSY}

The following indications for a testicular biopsy should be considered:

- obstructive azoospermia: confirmation of the presence of normal spermatogenesis may be desired before surgical correction of the obstruction is planned. This does not apply for men with a history of vasectomy or for men with congenital absence of the vas deferens, unless testicular volume is reduced or follicle-stimulating hormone is elevated. ${ }^{3}$

- testicular sperm extraction: multiple testicular biopsies are usually needed for sperm harvesting in men with NOA. Part of the specimen should be used for histological examination to predict the chance for future successful sperm harvesting and to diagnose CIS of the testis. ${ }^{32}$ Microdissection may improve the success of sperm harvesting. ${ }^{33}$

- diagnosis of CIS of the testis: risk factors for CIS are male infertility together with other risk factors, such as a history of cryptorchidism, testicular germ cell tumour and in the case of idiopathic testicular atrophy. Also, some ultrasosnographic abnormalities of the testis indicate the potential presence of CIS, especially testicular microlithiasis, an inhomogeneous testicular parenchyma and solid testicular lesions. Testicular lesions of unknown origin warrant an excision biopsy. ${ }^{34-38}$

\section{PREDICTIVE VALUE OF TESTICULAR BIOPSY FOR ASSISTED REPRODUCTIVE TECHNOLOGY}

In men with NOA, spermatozoa can be harvested from the testis in $50 \%-60 \% .^{31}$ Previous attempts to predict sperm retrieval from testis of men with NOA based on clinical parameters, such as testicular volume or reproductive hormones, have failed. ${ }^{31}$

In the literature, there is no consensus on the value of testicular histology for sperm retrieval: some authors conclude that testicular histology is of limited value, ${ }^{39}$ while others find it to be of major prognostic significance. ${ }^{30,40,41}$ It has been postulated that the lack of clarity may well arise from inaccurate identification of germ cells and confusing categorisation of biopsies. ${ }^{14}$ The description of the histological method is often not mentioned or very briefly described. Sperm retrieval is usually good in men with hypospermatogenesis and limited in men with Sertoli cell-only syndrome: Table 2 summarizes the results of studies that have compared the histological results of the testicular biopsy to the sperm retrieval rate. ${ }^{42-45}$ In regard to men with Klinefelter syndrome, the successful rate of sperm retrieval using TESE has ranged from $27 \%$ to $69 \%{ }^{46}$ These differences can be attributed to differences between the men, their age and the histological patterns within their testes. Thus, Schiff et al. ${ }^{43}$ observed a $71 \%$ sperm recovery rate among Klinefelter syndrome patients, while histological analyses revealed Sertoli cell-only syndrome in 33\% of men with Leydig cell hyperplasia and $67 \%$ with focal hypospermatogenesis. However, these results should be interpreted carefully since single testis biopsy is not representative to the whole organ. Finally, the procedure used may impact the outcome (microsurgical TESE was associated with higher sperm retrieval rate compared to the conventional TESE), as will the experience of the laboratories in identifying testicular sperm. ${ }^{43}$

Table 2 Percentage of sperm retrieval rates (SRR) in men with non-obstructive azoospermia according to the histological diagnosis using conventional TESE (cTESE) or microsurgical TESE (mTESE)

\begin{tabular}{|c|c|c|c|c|c|c|}
\hline \multirow[t]{3}{*}{ Study } & \multicolumn{6}{|c|}{$\operatorname{SRR}(\%)$} \\
\hline & \multicolumn{2}{|c|}{ Hypospermatogenesis } & \multicolumn{2}{|c|}{ Maturation arrest } & \multicolumn{2}{|c|}{ Sertoli cell-only syndrome } \\
\hline & cTESE & mTESE & cTESE & mTESE & cTESE & mTESE \\
\hline Okada et al. ${ }^{33}$ & 0 & 100 & 38 & 75 & 6 & 34 \\
\hline Ramasamy et al. ${ }^{40}$ & 50 & 81 & 20 & 44 & 29 & 41 \\
\hline Tsujimura et al. ${ }^{41}$ & 77 & 100 & 0 & 75 & 13 & 23 \\
\hline
\end{tabular}




\section{TESTICULAR BIOPSY DURING ORCHIDOPEXY}

Cryptorchidism is the most prevalent congenital disorder of the male genital tract with an incidence of $1 \%$ at the age of 1 year. Cryptorchidism is associated with an elevated risk for male infertility, especially for bilateral cases and testicular germ cell tumours. ${ }^{47-49}$ If left untreated during childhood, cryptorchidism will result in a progressive loss of germ cells. Orchidopexy is recommended in early childhood to ameliorate future fertility problems and to allow palpation of the gonad for the early detection of testicular cancer. In boys with a history of cryptorchidism, the life-time risk of developing a testicular malignancy ranges from $2 \%$ to $5 \%$, depending on the age of orchidopexy. ${ }^{50,51}$ CIS is the precursor cell of all testicular germ cell malignancies and is already present at birth. ${ }^{23}$ This raises the question if a testicular biopsy should be performed routinely during orchidopexy. Boys who are operated before the age of 12 years have a risk of $2 \%$ for developing a testicular tumour later in life. If, however, orchidopexy is performed during or after puberty, the risk for developing a testicular tumour is $5 \% .^{51}$ Therefore, a testicular biopsy is recommended in adolescents with cryptorchidism for detection of CIS of the testis. ${ }^{3}$

In a group of patients who underwent testicular biopsy at the time of orchidopexy for correction of crytorchodism, Hadziselimovic et al. ${ }^{51}$ observed that boys with unilateral crytorchidism and Ad spermatogonia detected in their testicular tissue had seven times higher sperm concentrations later in life compared to those with no Ad spermatogonia, irrespective of the age of surgical repair. Similar findings were reported in boys with bilateral cryptorchidism. The authors concluded that boys with cryptorchidism lacking Ad spermatogonia will develop infertility despite successful surgical treatment at any age. Also, they conclude that testicular biopsy during orchidopexy is of prognostic value for future fertility and should result in hormonal treatment after the operation to increase the number of germ cells. ${ }^{52}$ However, hormonal treatment of boys with cryptorchidism could also result in germ cell apoptosis and is therefore not recommended. ${ }^{53}$

\section{TESTICULAR BIOPSY AND NON-PALPABLE TESTICULAR LESIONS}

Scrotal ultrasound is a valuable tool in the evaluation of the testis and adjacent structures and is often used routinely in male infertility diagnostic work-up. Using ultrasound allows detection of several intratesticular abnormalities, such as microlithiasis and lesions of the gonads. Both conditions may be associated with testicular cancer. ${ }^{38}$ Palpable lesions and large testicular lesions are likely to be malignant with a probability as high as $95 \%$. Non-palpable lesions may be present in as many as a third of patients with severe male factor infertility. ${ }^{54}$ The aetiology of these lesions differs among studies, with some reporting a high proportion of malignancy, whereas other found the majority of lesions to be benign. ${ }^{55-57}$

Eifler et al. ${ }^{54}$ reviewed a total of 145 men who presented with severe infertility and underwent ultrasound examination. Among those, 49 were found to have abnormalities on ultrasound. Only one patient appeared to have a seminoma with intratesticular lesion greater than $10 \mathrm{~mm}$, and all other lesions were found to be benign with mean size ranging from 5 to $10 \mathrm{~mm}$. Toren et al ${ }^{58}$ followed 46 men with mean age of 35 years with ultrasound for 1 year with a mean number of ultrasounds of 2.8. The mean lesion diameter was $4.3 \mathrm{~mm}$ (range: $1-10 \mathrm{~mm}$ ). Among the 46 men, 38 patients showed a mean growth of the intratesticular lesions of $0.5 \mathrm{~mm}$ per year. Three patients underwent immediate surgery and five underwent surgery following a period of ultrasound follow-up.
Indications for surgery were interval growth in two patients and patient preference in six. One patient underwent radical orchiectomy for pure seminoma identified due to interval growth from 3 to $6 \mathrm{~mm}$ after 3 months. The other seven masses excised with partial orchiectomy were benign. ${ }^{58}$

From these studies it can be concluded that patients with small (less than $10 \mathrm{~mm}$ ) non-palpable intratesticular lesions detected on ultrasound during evaluation of male infertility may benefit from periodic ultrasound examination. In the case of growth of the initial lesions or additional risk factors for testicular germ cell tumours (TGCTs), testicular biopsy should be considered.

\section{DETECTION OF CIS OF THE TESTIS}

TGCTs are the most frequent malignancies in Caucasian males of 20-34 years of age. ${ }^{59}$ The disease specific survival of TGCTs in Europe is $97 \%$ at 1 year and $93 \%$ at 5 years, the highest survival rate for any malignant tumour in men. ${ }^{60}$ Despite this high cure rate, the annual increase in incidence of $2 \%-5 \%$ in Western European countries is a major concern. ${ }^{61}$ Twenty-three per cent of the men presenting a TGCT have metastases and need radiotherapy or chemotherapy with potentially serious side effects, including infertility. ${ }^{62}$

TGCTs, including seminomas and non-seminomas, have CIS as common precursor. ${ }^{63}$ CIS develops into invasive malignancy in $70 \%$ of the cases in 7 years and presumably in all patients over a longer period of time. ${ }^{64}$ CIS can be successfully treated with a low dose of radiotherapy or unilateral orchidectomy. Radiation therapy or orchidectomy prevents progression from CIS to an invasive TGCT and is likely to cure the patient. ${ }^{64}$ This avoids adjuvant chemotherapy and radiotherapy and the risk of development of long-term complications. After chemotherapy for testicular germ cell cancer, there is an increased risk for cardiovascular diseases, pulmonary fibrosis, nephrotoxicity and secondary malignancies. ${ }^{65}$ Therefore, efforts should be made to diagnose TGCT at the preinvasive stage. ${ }^{66}$ CIS can only be diagnosed by testicular biopsy, although we recently demonstrated CIS cells in semen using OCT $3 / 4$ immunohistochemistry. ${ }^{67}$ OCT $3 / 4$ staining allows rapid identification of CIS cells and is highly sensitive and specific. The percentage of false-negative biopsies is estimated as low as $0.5 \%$. This is supposedly due to the equal distribution of CIS throughout the testis. However, a growing number of studies and case reports show that CIS may also be present as a focal lesion in the testis and can result in a false-negative biopsy. ${ }^{59,68}$

Of all patients with unilateral testicular tumours, approximately $2 \%-5 \%$ harbour CIS in their contralateral testis that will progress into an invasive germ cell tumour over time. Controversies exists whether a routine contralateral biopsy should be performed in all men who are diagnosed with testicular cancer as it should only be offered if it provides a clear health benefit for the patient. Treating CIS in the contralateral testis will result in irreversible infertility and in approximately $20 \%$ cases, it will also cause hypogonadism. An alternative could be active surveillance for men who have been treated for TGCTs. According to the recommendations of the European Germ Cell Cancer Consensus Group, a testicular biopsy might be offered to high-risk patients for detecting contralateral CIS, i.e., patients with a testicular volume less than $12 \mathrm{ml}$, men with a history of cryptorchidism and in the case of ultrasonographic abnormalities. $^{18}$

Non-invasive test for the detection of CIS of the testis may open the possibility of screening men with an increased risk of TGCTs. ${ }^{38,67}$ This 
applies to men with infertility, a history of cryptorchidism and testicular tumour, and men with atrophic testes. Ultrasonographic abnormalities of the testis further increase the risk of CIS and TGCTs and warrant testicular histology.

There is a wide global discrepancy in testicular cancer incidence rates. Testicular cancer remains a disease predominantly of men descended from European populations, in particular, Northern European populations with incidence rates that are almost twice more than that of the United States and Asian countries. ${ }^{69}$ This also accounts for the difference in CIS rates between these countries. Although its aetiology has yet to be clarified, environmental and genetic factors may play an important role. ${ }^{70}$ Due to the low incidence and low risk of TGCT in men with testicular microlithiasis in the United States, they do not recommend screening for CIS of the testis but advocate self examination. ${ }^{71}$ Recently, van Casteren et.al. ${ }^{72}$ proposed a new algorithm for the management of patients with testicular microlithiasis (Figure 3): associated risk factors for testicular germ cell cancer, such as infertility, cryptorchidism, testicular atrophy and a history of testicular germ cell cancer, and the age of the patient decide if the patient is advised to have a testicular biopsy. If none of these risk factors are present, self-examination will suffice.

\section{CONCLUSIONS}

Testicular biopsies can be performed for diagnostic and therapeutic reasons. Since testicular spermatozoa can be successfully used for ICSI, it is strongly recommended to perform cryopreservation of (part of the) testicular tissue for future ICSI, if spermatozoa are available. A diagnostic testicular biopsy may be performed in men with azoospermia, normal testicular volume and normal reproductive hormones to differentiate between obstructive and nonobstructive azoospermia. Furthermore, in men with signs of testicular dysgenesis on ultrasound, such as an inhomogeneous testicular architecture and testicular microlitiasis, a biopsy may show CIS of the testis, the precursor of a testicular tumour. We recommend that all

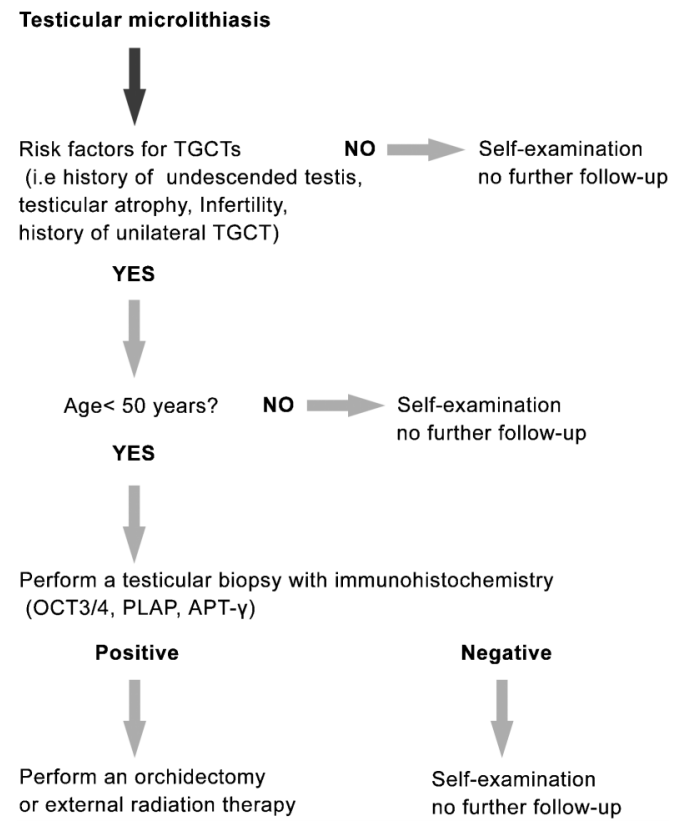

Figure 3 Algorithm for the management of testicular microlithiasis. CIS; carcinoma in situ; PLAP, placental alkaline phosphatase; TFAP2C, AP-2gamma, transcription factor activator protein-2gamma; TGCT: testicular germ cell tumour. testicular biopsies, those performed for TESE, as well as those for assessing spermatogenic status, should be evaluated for the presence of CIS.

\section{COMPETING FINANCIAL INTERESTS}

The authors declare no competing financial interests.

1 Nieschlag E, Behre HM. Andrology, Male Reproductive Health and Dysfunction. 2nd ed., Chapter 5 Berlin: Springer-Verlag; 2000. pp 83-7.

2 Skakkebaek NS, Rajpert-de Meyts E, Main KM. Testicular dysgenesis syndrome: an increasingly common developmental disorder with environmental aspects. Hum Reprod 2001; 16: 972-78.

3 Dohle GR, Jungwirth A, Colpi G, Giwercman A, Diemer T. European Association of Urology Guidelines on Male Infertility. 2010 ed. Arnhem: EAU; 2010. pp 1-70.

4 Devroey P, Liu J, Nagy Z, Tournaye H, Silber SJ et al. Normal fertilization of human oocytes after testicular sperm extraction and intracytoplasmic sperm injection. Fertil Steril 1994; 62: 639-41.

5 Berthelsen JG, Skakkebaek NE. Value of testicular biopsy in diagnosing carcinoma in situ testis. Scand J Urol Nephrol 1981; 15: 165-8.

6 Beliveau ME, Turek PJ. The value of testicular 'mapping' in men with non-obstructive azoospermia. Asian J Androl 2011; 13: 225-30.

7 Carpi A, Agarwal A, Sabanegh E, Todeschini G, Balercia G. Percutaneous biopsy of the testicle: a mini review with a proposal flow chart for non-obstructive azoospermia. Ann Med 2011; 43: 83-9.

8 Rammou-Kinia R, Anagnostopoulou I, Tassiopoulos F, Lykourinas M. Fine needle aspiration of the testis. Correlation between cytology and histology. Acta Cytol 1999; 43: 991-8.

9 Donoso P, Tournaye H, Devroey P. Which is the best sperm retrieval technique for nonobstructive azoospermia? A systematic review. Hum Reprod Update 2007; 13: 53949

10 Bettella A, Ferlin A, Menegazzo M, Ferigo M, Tavolini IM et al. Testicular fine needle aspiration as a diagnostic tool in non-obstructive azoospermia. Asian J Androl 2005; 7: 289-94.

11 Ishikawa T, Yamaguchi K, Chiba K, Takenaka A, Fujisawa M. Serum hormones in patients with nonobstructive azoospermia after microdissection testicular sperm extraction. J Urol 2009; 182: 1495-9.

12 Takada S, Tsujimura A, Ueda T, Matsuoka Y, Takao T et al. Androgen decline in patients with nonobstructive azoospemia after microdissection testicular sperm extraction. Urology 2008; 72: 114-8.

13 van Casteren NJ, Boellaard WP, Dohle GR, Weber RF, Kuizinga MC et al. Heterogeneous distribution of ITGCNU in an adult testis: consequences for biopsybased diagnosis. Int J Surg Pathol 2008; 16: 21-4

14 McLachlan RI, Rajpert-de Meyts E, Hoei-Hansen CE, de Kretser DM, Skakkebaek NE. Histological evaluation of the human testis-approaches to optimizing the clinical value of the assessment: mini review. Hum Reprod 2007; 22: 2-16.

15 Oosterhuis JW, Stoop H, Dohle G, Boellaard W, van Casteren N et al. A pathologist's view on the testis biopsy. Int J Androl 2011; 34(4 Pt 2): e14-9.

16 Hanevik HI, Isfoss BL, Bergh A, Friberg M, Kahn JA. Improved diagnostic accuracy of testicular biopsies for infertility through simplified criteria and a dedicated pathologist. Anal Quant Cytol Histol 2010; 32: 214-8.

17 Cooperberg MR, Chi T, Jad A, Cha I, Turek PJ. Variability in testis biopsy interpretation: implications for male infertility care in the era of intracytoplasmic sperm injection. Fertil Steril 2005; 84: 672-7.

18 Krege S, Beyer J, Souchon R, Albers P, Albrecht W et al. European consensus on diagnosis and treatment of germ cell cancer: a report of the European Germ Cell Cancer Consensus Group (EGCCCG). Ann Oncol 2004; 15: 1377-99.

19 Latendresse JR, Warbrittion AR, Jonassen H, Creasy DM. Fixation of testes and eyes using a modified Davidson's fluid: comparison with Bouin's fluid and conventional Davidson's fluid. Toxicol Pathol 2002; 30: 524-33.

20 Harleman JH, Nolte T. Testicular toxicity: regulatory guidelines - the end of Formaldehyde fixation? Toxicol Pathol 1997; 24: 414-7.

21 Dieckmann KP, Loy V. False-negative biopsies for the diagnosis of testicular intraepithelial neoplasia (TIN)—an update. Eur Urol 2003; 43: 516-21.

22 van Casteren NJ, de Jong J, Stoop H, Steyerberg EW, de Bekker-Grob EW et al. Evaluation of testicular biopsies for carcinoma in situ: immunohistochemistry is mandatory. Int J Androl 2009; 32: 666-74.

23 Honecker F, Stoop H, de Krijger RR, Chris Lau YF, Bokemeyer C et al. Pathobiological implications of the expression of markers of testicular carcinoma in situ by fetal germ cells. J Pathol 2004; 203: 849-57.

24 Looijenga LH, Gillis AJ, Stoop H, Biermann K, Oosterhuis JW. Dissecting the molecular pathways of (testicular) germ cell tumour pathogenesis; from initiation to treatment-resistance. Int J Androl 2011; 12: 1365-2605.

25 Johnsen SG. Testicular biopsy score count-a method for registration of spermatogenesis in human testis: normal values and results in 335 hypogonadal males. Hormones 1970; 1: 2

26 DeKretser DM, Holstein AF. Testicular biopsy and abnormal germ cells. In: Hafez ESEHuman Semen and Fertility Regulation in Men St Louis, MO: Mosby; 1976332-43. 
27 Holstein AF, Schulze W, Davidoff M. Understanding spermatogenesis is a prerequisite for treatment. Reprod Biol Endocrinol 2003; 1: 107.

28 Silber SJ, Nagy Z, Devroey P, Tournaye H, van Steirteghem AC. Distribution of spermatogenesis in the testicles of azoospermic men: the presence or absence of spermatids in the testes of men with germinal failure. Hum Reprod 1997; 12 : 2422-8.

29 Nistal M, Paniagua R. Testicular biopsy. Contemporary interpretation. Urol Clin North Am 1999; 26: 555-93.

30 Shulze W, Thoms F, Knuth UA. Testicular sperm extraction: comprehensive analysis with simultaneously performed histology in 1418 biopsies from 766 subfertile men. Hum Reprod 1999; 14: 82-96.

31 Tournaye H, Verheyen G, Nagy P, Ubaldi F, Goossens A et al. Are there any predictive factors for successful testicular sperm recovery in azoospermic patients? Hum Reprod 1997; 12: 80-6.

32 Schlegel PN. Testicular sperm extraction: microdissection improves sperm yield with minimal tissue excision. Hum Reprod 1999; 14: 131-5.

33 Okada H, Dobashi M, Yamazaki T, Hara I, Fujisawa M et al. Conventional versus microdissection testicular sperm extraction for non obstructive azoospermia. J Urol 2002; 168: 1063-7.

34 Skakkebaek NE. Possible carcinoma-in-situ of the testis. Lancet 1972; 9: 516-7.

35 Møller H. Skakkebaek NE. Risk of testicular cancer in subfertile men: case-control study. Br Med J 1999; 318: 559-62.

36 Giwercman A, Bruun E, Frimodt-Moller C, Skakkebaek NE. Prevalence of carcinoma in situ and other histopathological abnormalities in testes of men with a history of cryptorchidism. J Urol 1989; 142: 998-1001.

37 Dieckmann KP, Loy V. Prevalence of contralateral testicular intraepithelial neoplasia in patients with testicular germ cell neoplasms. J Clin Oncol 1996; 14: 3126-32.

38 Elzinga-Tinke JE, Sirre ME, Looijenga LH, van Casteren N, Wildhagen MF et al. The predictive value of testicular ultrasound abnormalities for carcinoma in situ of the testis in men at risk for testicular cancer. Int J Androl 2010; 1: 597-603.

39 Hauser R, Yogev L, Paz G, Yavetz H, Azem F et al. Comparison of efficacy of two techniques for testicular sperm retrieval in nonobstructive azoospermia: multifocal testicular sperm extraction versus multifocal testicular sperm aspiration. J Androl 2006; 27: 28-33

40 Ramasamy R, Schlegel PN. Microdissection testicular sperm extraction: effect of prior biopsy on success of sperm retrieval. J Urol 2007; 177: 1447-9.

41 Tsujimura A, Matsumiya K, Miyagawa Y, Tohda A, Miura H et al. Conventional multiple or microdissection testicular sperm extraction: a comparative study. Hum Reprod 2002; 17: 2924-9.

42 Seo JT, Park YS, Lee JS. Successful testicular sperm extraction in Korean Klinefelter syndrome. Urology 2004; 64: 1208-11.

43 Schiff JD, Palermo GD, Veeck LL, Goldstein M, Rosenwaks Z et al. Success of testicular sperm extraction [corrected] and intracytoplasmic sperm injection in men with Klinefelter syndrome. J Clin Endocrinol Metab 2005; 90: 6263-7.

44 Koga M, Tsujimura A, Takeyama M, Kiuchi H, Takao T et al. Clinical comparison of successful and failed microdissection testicular sperm extraction in patients with nonmosaic Klinefelter syndrome. Urology 2007; 70: 341-5.

45 Yarali H, Polat M, Bozdag G, Gunel M, Alpas I et al. TESE-ICSI in patients with nonmosaic Klinefelter syndrome: a comparative study. Reprod Biomed Online 2009; 18: 756-60.

46 Selice R, Di Mambro A, Garolla A, Ficarra V, lafrate M et al. Spermatogenesis in Klinefelter syndrome. J Endocrinol Invest 2010; 33: 789-93.

47 Lee PA. Fertility after cryptorchidism: epidemiology and other outcome studies. Urology 2005; 66: 427-31.

48 Cortes D, Thorup JM, Visfeldt J. Cryptorchidism: aspects of fertility and neoplasms. A study including data of 1,335 consecutive boys who underwent testicular biopsy simultaneously with surgery for cryptorchidism. Horm Res 2001; 55: 21-7.
49 Herrinton LJ, Zhao W, Husson G. Management of cryptorchidism and risk of testicular cancer. Am J Epidemiol 2003; 157: 602-5.

50 Pettersson A, Richiardi L, Nordenskjold A, Kaijser M, Akre O. Age at surgery for undescended testis and risk of testicular cancer. N Engl J Med 2007; 3: 1835-41.

51 Hadziselimovic F, Hoecht B. Testicular histology related to fertility outcome and postpubertal hormone status in cryptorchidism. Klin Padiatr 2008; 220: 302-7.

52 Hadziselimović F, Herzog B. Treatment with a luteinizing hormone-releasing hormone analogue after successful orchiopexy markedly improves the chance of fertility later in life. J Urol 1997; 158: 1193-5.

53 Ritzen EM, Bergh A, Bjerknes R, Christiansen P, Cortes D et al. Nordic consensus on treatment of undescended testes. Acta Paediatr 2007; 96: 638-43.

54 Eifler JB Jr, King P, Schlegel PN. Incidental testicular lesions found during infertility evaluation are usually benign and may be managed conservatively. J Uro/ 2008; 180: 261-4.

55 Carmignani L, Gadda F, Mancini M, Gazzano G, Nerva F et al. Detection of testicular ultrasonographic lesions in severe male infertility. J Urol 2004; 172: 1045-7.

56 Connolly SS, D'Arcy FT, Gough N, McCarthy P, Bredin HC et al. Carefully selected intratesticular lesions can be safely managed with serial ultrasonography. BJU Int 2006; 98: 1005-7.

57 Sheynkin YR, Sukkarieh T, Lipke M, Cohen HL, Schulsinger DA. Management of nonpalpable testicular tumors. Urology 2004; 63: 1163-7.

58 Toren PJ, Roberts M, Lecker I, Grober ED, Jarvi K et al. Small incidentally discovered testicular masses in infertile men-is active surveillance the new standard of care? J Urol 2010; 183: 1373-7.

59 Dieckmann KP, Pichlmeier U. Clinical epidemiology of testicular germ cell tumors. World J Urol 2004; 22: 2-14.

60 Gori S, Porrozzi S, Roila F, Gatta G, de Giorgi U et al. Germ cell tumours of the testis. Crit Rev Oncol Hematol 2005; 53: 141-64.

61 Huyghe E, Matsuda T, Thonneau P. Increasing incidence of testicular cancer worldwide: a review. J Urol 2003; 170: 5-11.

62 Petersen PM, Giwercman A, Daugaard G, Rørth M, Petersen JH et al. Effect of graded testicular doses of radiotherapy in patients treated for carcinoma-in-situ in the testis. J Clin Oncol 2002; 15: 1537-43.

63 Skakkebaek NE, Berthelsen JG, Giwercman A, Müller J. Carcinoma-in-situ of the testis: possible origin from gonocytes and precursor of all types of germ cell tumours except spermatocytoma. Int J Androl 1987; 10: 19-28.

64 Giwercman A, Skakkebaek NE. Carcinoma in situ of the testis: biology, screening and management. Eur Urol 1993; 23(Suppl 2)19-21.

65 Travis LB, Beard C, Allan JM, Dahl AA, Feldman DR et al. Testicular cancer survivorship: research strategies and recommendations. J Nat Cancer Inst 2010, 102: $1114-30$.

66 Ilic D, Misso ML. Screening for testicular cancer. Cochrane Database Syst Rev 2011: 2: CD007853.

67 van Casteren NJ, Stoop H, Dohle GR, de Wit R, Oosterhuis JW et al. Noninvasive detection of testicular carcinoma in situ in semen using OCT3/4. Eur Urol 2008; 54: 153-8.

68 Kliesch S, Thomaidis T, Schutte B, Puhse G, Kater B et al. Update on the diagnostic safety for detection of testicular intraepithelial neoplasia (TIN). APMIS 2003; 111: 70-4.

69 Chia VM, Quraishi SM, Devesa SS, Purdue MP, Cook MB et al. International trends in the incidence of testicular cancer, 1973-2002. Cancer Epidemiol Biomarkers Prev 2010; 19: 1151-9.

70 Sharpe RM, Skakkebaek NE. Testicular dysgenesis syndrome: mechanistic insights and potential new downstream effects. Fertil Steril 2008; 89(2 Suppl): e33-8.

71 US Preventive Services Task Force. Screening for testicular cancer: U.S. Preventive Services Task Force. Ann Intern Med 2011; 154: 483-6.

72 van Casteren NJ, Looijenga LH, Dohle GR. Testicular microlithiasis and carcinoma in situ overview and proposed clinical guideline. Int J Androl 2009; 32: 279-87. 